\title{
ENVIRONMETAL FRIENDLY METHOD IN THE SUGAR-BEET PRODUCTION FOR THE COLOURANTS REMOVAL
}

\author{
Zita Šereš ${ }^{1}$, Gyula Vatai $^{2}$, Ljubica Dokić ${ }^{1}$, Dragana Šoronja-Simović ${ }^{1}$, Cecília Hodúr ${ }^{3}$, \\ Bojana Ikonić ${ }^{1}$, Ivana Nikolić ${ }^{1}$, Biljana Pajin ${ }^{1}$ \\ ${ }^{1}$ Faculty of Technology, University of Novi Sad, 21000, Bul. cara Lazara 1, Novi Sad, Serbia \\ ${ }^{2}$ Faculty of Food Science, Corvinus University, H-1114, Villányi út 29-43, Budapest, \\ Hungary \\ ${ }^{3}$ Faculty of Engineering, University of Szeged, H- 6700, Moszkva krt. 6-8, Szeged, Hungary \\ ivananikolic@tf.uns.ac.rs
}

\begin{abstract}
Despite the fact that the sugar industry is one of the causes of the environmental pollution, not enough has been done on its improvement. According to CEFS, specific energy consumption was 31.49 $\mathrm{kWh} / 100 \mathrm{~kg}$ sugar beet. While the overall water used is about $15 \mathrm{~m}^{3} / \mathrm{t}$ sugar beet processed, the consumption of fresh water is $0.25-0.4 \mathrm{~m}^{3} / \mathrm{t}$ sugar beet processed, or even less in modern sugar factories. The separation operation deserves special attention because of its significant consumption of water end energy. Ultrafiltration could be one of the solutions for energy saving and more effective separation of coloured compounds (which during the crystallisation build into the sucrose crystals) from intermediate products from which sucrose directly crystallises.

The aim of this experimental work is to determine the influence of operating parameters on the efficiency on coloured matter removal in high concentrated syrup. In this work syrup solution, which is an intermediate product in the phase of sucrose crystallisation, with $60 \%$ dry matter content, is the main feed. Experimental investigations were performed on $20 \mathrm{~nm}$ ceramic tubular membrane. Effects of colour removal on syrup solution are investigated at 60 and $80^{\circ} \mathrm{C}$, in the range of transmembrane pressure between 4 and 10 bars. Optimal values of flow rates are chosen between 100 and $400 \mathrm{~L} / \mathrm{h}$. For defining the effects of the membrane separation process, permeate flux are determined.

According to mentioned conditions colour is by $35-40 \%$ in average, and turbidity is by $80 \%$ in average lower according to the feed. The permeate flux could be reached is $45 \mathrm{~L} / \mathrm{m}^{2} \mathrm{~h}$ at flow rate 400 $\mathrm{L} / \mathrm{h}$ and at $80^{\circ} \mathrm{C}$.
\end{abstract}

Key words: sugar industry, ultrafiltration, non-sucrose compunds, colour remoal

\section{INTRODUCTION}

The white sugar is the final product of sugar industry. It has to satisfy specific quality demands and one of them is the colour of the crystal sugar. Ensuring colour quality parameters of white sugar used to be difficult, especially when the quality of the processed beet is poor (Poel Van der et al., 1998).

A purified sugar syrup, which is to be crystallized, contains undesired non-sucrose compounds, diluted in water. Coloured compounds are the most undesirable non-sucrose compounds, due to intensive colour. These compounds tend to build into the sucrose crystals during the crystallisation, so the general tendency is that the syrups from which sucrose directly crystallize should have as low content coloured matter as possible. The removal of the undesired compounds is one of the severe problems in sugar technology. As energy consumption of sugar production is high $(200-300 \mathrm{kWh} / \mathrm{t}$ beet), environmental pollution needs to be addressed, too. According to CEFS, specific energy consumption was $31.49 \mathrm{kWh} / 100$ $\mathrm{kg}$ sugar beet. While the overall water used is about $15 \mathrm{~m}^{3} / \mathrm{t}$ sugar beet processed, the 
consumption of fresh water is $0.25-0.4 \mathrm{~m}^{3} / \mathrm{t}$ sugar beet processed, or even less in modern sugar factories (EC BAT 2003; EC BAT 2006). Because of this reason the possibility of application of new separation techniques utilising membranes is thoroughly investigated. Considering the existing technology demands of large investments, our strategy was to find such membrane separation technique which could be inserted in the existing technology process of sugar production. It is stated that the crystallization in ultrafiltered juices is 1.2 times faster than in the juices conventionally purified.

Membrane separation studies were focused on finding the most appropriate membrane material with related properties (Poel Van der et al., 1998; Bubik et al. 1998), as well as optimal process variables which might guarantee the content of undesired compounds in the product to be low as possible (Gosh, Balakrishnan, 2003). As the syrup, sucrose crystallize from, represents a complex system with large and small molecules, the selection of adequate membrane appears to be a problem. Important is to provide easy passing of sucrose molecules and molecules that causes turbidity and colour should be retained. It is impossible to avoid passing the molecules smaller than sucrose through membrane with classical UF process. The working temperature is also important parameter. In sugar industry the working temperature is between $70-90^{\circ} \mathrm{C}$. Using polymer membranes could not be reached that temperature level. Mineral membranes are stable at higher temperatures (Decloux at al., 2003) .

To make membrane separation process applicable in sugar processing industry, permeate flux should be improved at first place. Ultrafiltration of sugar syrups are characterized by a decline in permeate flux with filtration time because of concentration polarization and progressive membrane fouling (Lipnizki et al. 2006; Gyura et al. 2005).

The final aim of the experiments was to separate high molecular coloured compounds from raw sugar syrup which are subjected to final product crystallisation (Šereš et al. 2010). The aim of this experimental work is to determine the influence of operating parameters on the efficiency on coloured matter removal in high concentrated syrup. In this work syrup solution, which is an intermediate product in the phase of sucrose crystallisation, with $60 \%$ dry matter content, is the main feed. Experimental investigations were performed on $20 \mathrm{~nm}$ ceramic tubular membrane. Effects of colour removal on syrup solution are investigated at 60 and $80^{\circ}$ $\mathrm{C}$, in the range of transmembrane pressure between 4 and 10 bars. Optimal values of flow rates are chosen between 100 and $400 \mathrm{~L} / \mathrm{h}$. For defining the effects of the membrane separation process, permeate flux are determined.

\section{MATERIAL and METHODS}

Row sugar syrup is used for the investigation of coloured matter separation by UF. Its basic characteristics corresponded to regular technological quality, purity is $97.11 \%$, which means that the syrup contains $97.11 \%$ sugar calculated to dry matter.

The laboratory UF equipment was set up at the Faculty of Food industry, "Corvinus" University in Budapest. The cross-flow filtration was realized on ceramic tubular membrane. The power of the pump for ultrafiltration was $0.25 \mathrm{~kW}$. The flow diagram of the setup is shown in Fig.1.

The membranes studied were Membralox membranes (SCT, Bazet, France), single channel type, $250 \mathrm{~mm}$ long, with $6.8 \mathrm{~mm}$ inner diameter. The membranes were of $20 \mathrm{~nm}$ pore diameter and were made of a zirconium oxide layer on a aluminium oxide support. The useful membrane surface was $4.62 \times 10^{-3} \mathrm{~m}^{2}$.

The row sugar syrup was diluted exactly to $60^{\circ} \mathrm{Bx}$ dry matter content. It was investigated the possibility of microfiltration of syrups with high dry matter content.

Experiments were performed in accordance with the plan presented in a Table 1, where the lower and the upper boundaries of the independent variables are given. 


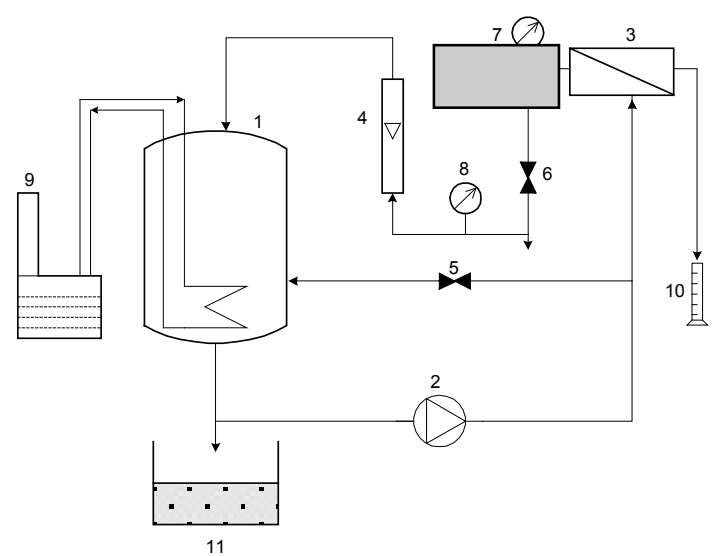

Figure 1. Laboratory setup for ultrafiltration: 1 - feed tank, 2 - pump, 3 - module with membrane, 4 - rotameter, 5, 6 - valves , 7 - manometer, 8 - thermometer, 9 - thermostat, 10 - vessel for permeate, 11 - vessel for retentate

Table 1. Plan of experiments - boundaries of independent variables

\begin{tabular}{|l|l|l|}
\hline \multirow{2}{*}{ Parameters } & \multicolumn{2}{|l|}{ Membrane 20 nm } \\
\cline { 2 - 3 } & $\begin{array}{l}\text { Lower } \\
\text { level }\end{array}$ & $\begin{array}{l}\text { Upper } \\
\text { level }\end{array}$ \\
\hline $\mathrm{q}[1 / \mathrm{h}]$ & 100 & 400 \\
\hline $\mathrm{T}\left[{ }^{\circ} \mathrm{C}\right]$ & 60 & 80 \\
\hline TMP $[$ bar $]$ & 2 & 10 \\
\hline
\end{tabular}

A full factorial design was applied and flow rate (q), temperature $(\mathrm{T})$ and transmembrane pressure $(\mathrm{TM} P)$ were kept at different levels while time was continually measured together with the measurements of three dependent variables: flux $(\mathrm{J})$, colour change $(\Delta B)$.

The permeate colour change is expressed as a difference between permeate and syrup colour divided by the colour of the initial syrup. The colour is quantified by the absorbance, measured on a spectrophotometer at $420 \mathrm{~nm}$.

As for the reproducibility of the results, only those measurements were repeated several times which gave significantly different values when twice repeated.

\section{RESULTS and DISSCUSSION}

The removed amount of the coloured compounds from the syrup is the key factor for this investigations. After the analyzing the experimental results in STATISTICA 8.0 a 3D diagram was constructed and presented on the picture 2. the removed amount coloured compounds from the syrup. With ultrafiltration, using ceramic membrane with pore size of $20 \mathrm{~nm}$, for about $35 \%$ of color matter could be removed. From figure 2 . could be seen that this decolorization value could be reached while pressure is held over 8 bars and flow rate between $300-350 \mathrm{~L} / \mathrm{h}$. 


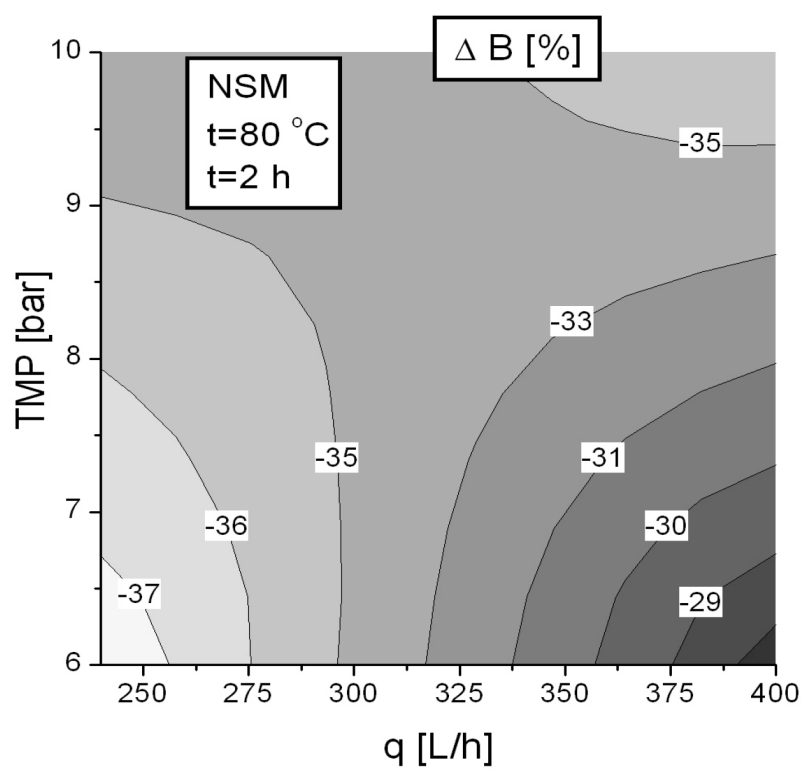

Figure 2. Coloure change depending on trasmembrane pressure (TMP) and flow rate (Q) at temperature of $80^{\circ} \mathrm{C}$ and after 2 hours of ultrafiltration

On the next figure 3. The influence of the pressure on the coloured compounds removal are showed. The percentage of the removed coloured compunds from the sugar syrup are showed at transmembrane pressures of 6 and 10 bars, flow rate at $250 \mathrm{~L} / \mathrm{h}$. It could be noticed that at transmembrane pressure of 6 bars around $10 \%$ more coloured compound could be removed according to the removed coloured compound on 10 bars. Reason for it is definetly the high pressure which presses the compounds through the pores of the membrane and more compounds passes through the pores into the permeate, while on lower pressure that effect is not so expressed.

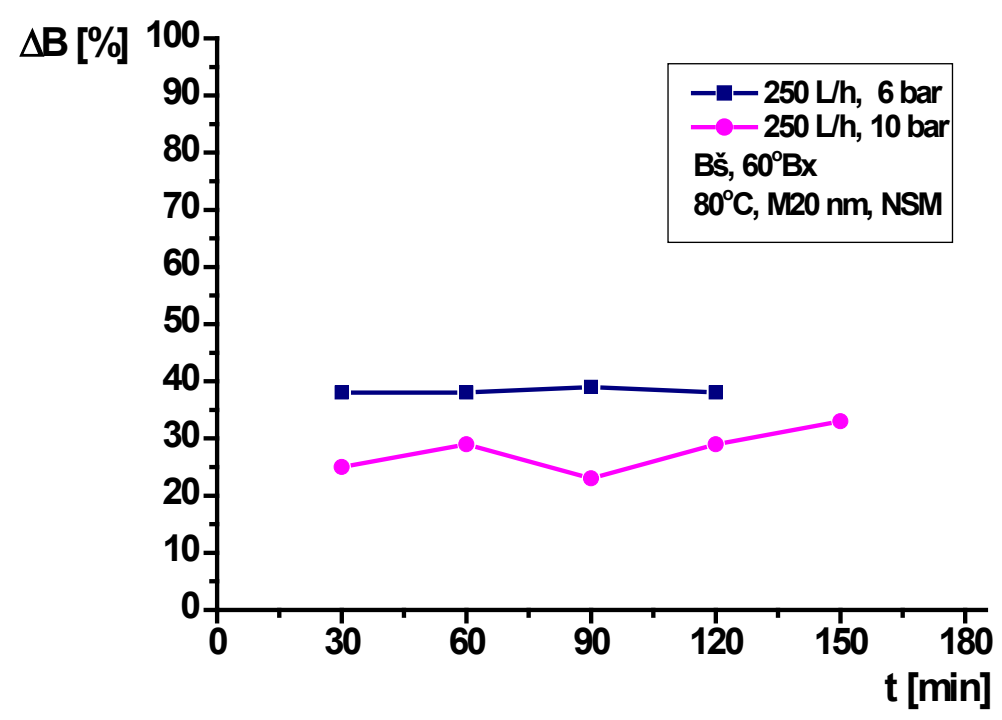

Figure 3. The percantage of the removed coloured compund during ultrafiltration at flow rate of $250 \mathrm{~L} / \mathrm{h}$ and on different transmembrane pressure 
After the investigation about the colourants removal, the permeate flux were observed too. Due to the fact, that sugar factories working temperature are mostly at $80^{\circ} \mathrm{C}$ and syrups has high viscosity, the influence of the temperature are invetigated on the permeate flux (picture 4.). On the picture 4. can be seen that the highest flux, which could be reachad is at $80^{\circ} \mathrm{C}$ and it is cca. $20 \mathrm{~L} / \mathrm{m}^{2} \mathrm{~h}$. With the temperature increase, the pereate flux increases too. It is expained by that, with temperature increase the viscosity of the syrup decreaases significantly. In this case the sugar syrup with dry matter content of $60{ }^{\circ} \mathrm{Bx}$ on $80^{\circ} \mathrm{C}$ has viscosity about $5.20 \mathrm{mPas}$, while at $60^{\circ} \mathrm{C}$ the syrup viscosity increases two times and it is 9,66 mPas.

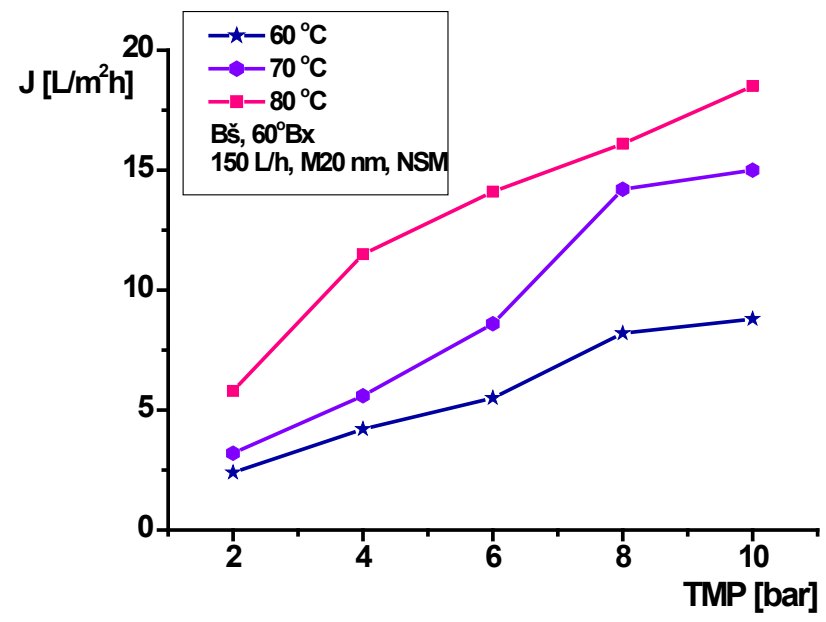

Figure 4. Pereate flux dependence on transmembrane pressure at different tempereratures and flow rate $150 \mathrm{~L} / \mathrm{h}$

\section{CONCLUSIONS}

Based on experiments of UF of row sugar syrup, with dry matter content of $60{ }^{\circ} \mathrm{Bx}$ could be concluded the following:

1. The best flux for ultrafiltration with ceramic membranes of $20 \mathrm{~nm}$ pore sizes could be reached at temperature about $80{ }^{\circ} \mathrm{C}$, flow rate above $300 \mathrm{~L} / \mathrm{h}$ and pressure above 8 bars.

2. Decolorization of about $35 \%$ could be reached while the pressure is held over 8 bars and flow rate between $300-350 \mathrm{~L} / \mathrm{h}$.

3. with temperature increase the viscosity of the syrup decreaases significantly. In this case the sugar syrup with dry matter content of $60{ }^{\circ} \mathrm{Bx}$ on $80^{\circ} \mathrm{C}$ has viscosity about $5.20 \mathrm{mPas}$, while at $60^{\circ} \mathrm{C}$ the syrup viscosity increases two times and it is $9,66 \mathrm{mPas}$.

\section{ACKNOWLEDGEMENT}

The investigations are supported by the Serbian Ministry of Science and Education (Project no. TR31014). Investigations are carried on in the frame of the IPA CBC project HUSRB/1203/221/196 WATERFRIEND project. 


\section{REFERENCES}

Bubnik, Z. Hinkova, A. Kadlec. P. (1998). Crossflow micro- and UF applied on ceramic membranes in inpure sugar solutions. Czeh J. of Food Sci. 16(1): 29-35

Decloux, M. Tatoud, L., Mersad A. (2000). Removal of colorants and polysaccharides from raw cane sugar remelts by UF. Zuckerindustrie, 125, 106-110.

European Commision: Reference Document on Best Available Techniques in Common Waste Water and Waste Gas Treatment / Management Systems in the Chemical Sector. February 2003 (pdf), http://eippcb.jrc.es (accessed 10/09/2012).

European Commision: Reference Document on Best Available Techniques in the Food, Drink and Milk Industries. Dated January 2006 (pdf), http://eippcb.jrc.es_(accessed 10/09/2012).

Ghosh, A.M, Balakrishnan, M. (2003). Pilot demonstration of sugar cane juice UF in an Indian sugar factory. J. Food Eng. 58: 143-150.

Gyura, J., Šereš, Z., Eszterle, M. (2005). Influence of operating parameters on separation of green syrup colored matter from sugar beet by ultra- and nanofiltration. Journal of Food Engineering, 66, 89-96, 0260-8774.

Lipnizki, F.; Carter, M. Tragardh, G. (2006). Applications processes in the beet and cane sugar production. Zuckerindustrie . 131, 29-38.

Poel, Van der, P., Schiweck, H., Schwartz, T. (1998). Sugar Technology - Beet and Cane Sugar Manufacture. Verlag Dr. Albert Bartens, 978-3-87040-065-1, KG - Berlin

Šereš, Z., Gyura, J., Djurić, M., Vatai, Gy., Jokič, A. (2010). Separation of non-sucrose compounds from sugar-beet syrup by ultrafiltration with ceramic membrane containing static mixer, Desalnation 250, 136-143. 